\title{
Measles resurgence prompts debate over mandatory vaccination
}

\author{
口 Cite as: CMAJ 2019 June 17;191:E676-7. doi: 10.1503/cmaj.109-5763
}

Posted on cmajnews.com on May 30, 2019.

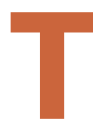
he growing number of measles cases across Canada has reignited debate about mandatory vaccination. Ontario and New Brunswick require students to have certain vaccines, including measles, for school attendance. It is surprisingly easy, however, to get an exemption.

Parents can obtain immunization exemptions for their children based on conscientious objection or religious beliefs. Ontario requires parents to watch an educational video on immunization before submitting a request. In New Brunswick, parents can simply provide a written statement of objection.

In both provinces, physicians can provide medical exemptions, but with other types of exemptions so easy to get, doctors have not been subjected to pressure from parents to provide them. Medical exemption for immunization is rare. The situation is quite different in three American states Mississippi, West Virginia and California - where the only exemptions allowed are for medical reasons.

"We have some providers that, on a Monday, are submitting [an exemption] and they are okay with submitting it. And then on the Wednesday, they may reach out to us and tell us they've changed their mind," says Christie Levi, a program coordinator with the Mississippi State
Department of Health. She thinks parental pressure is the reason why many doctors submit exemptions they later regret.

Mandatory programs had a positive impact in jurisdictions where exemptions are allowed only for medical reasons, especially in areas with a centralized review process, like Mississippi. The state had 99.4\% childhood immunization to guide decisionmakers, according to a 2018 review published in Vaccine. Its authors recommend futher study of the impact of such programs and caution against making decisions before there are sound data. They also say authorities should learn from the unintended consequences of mandatory

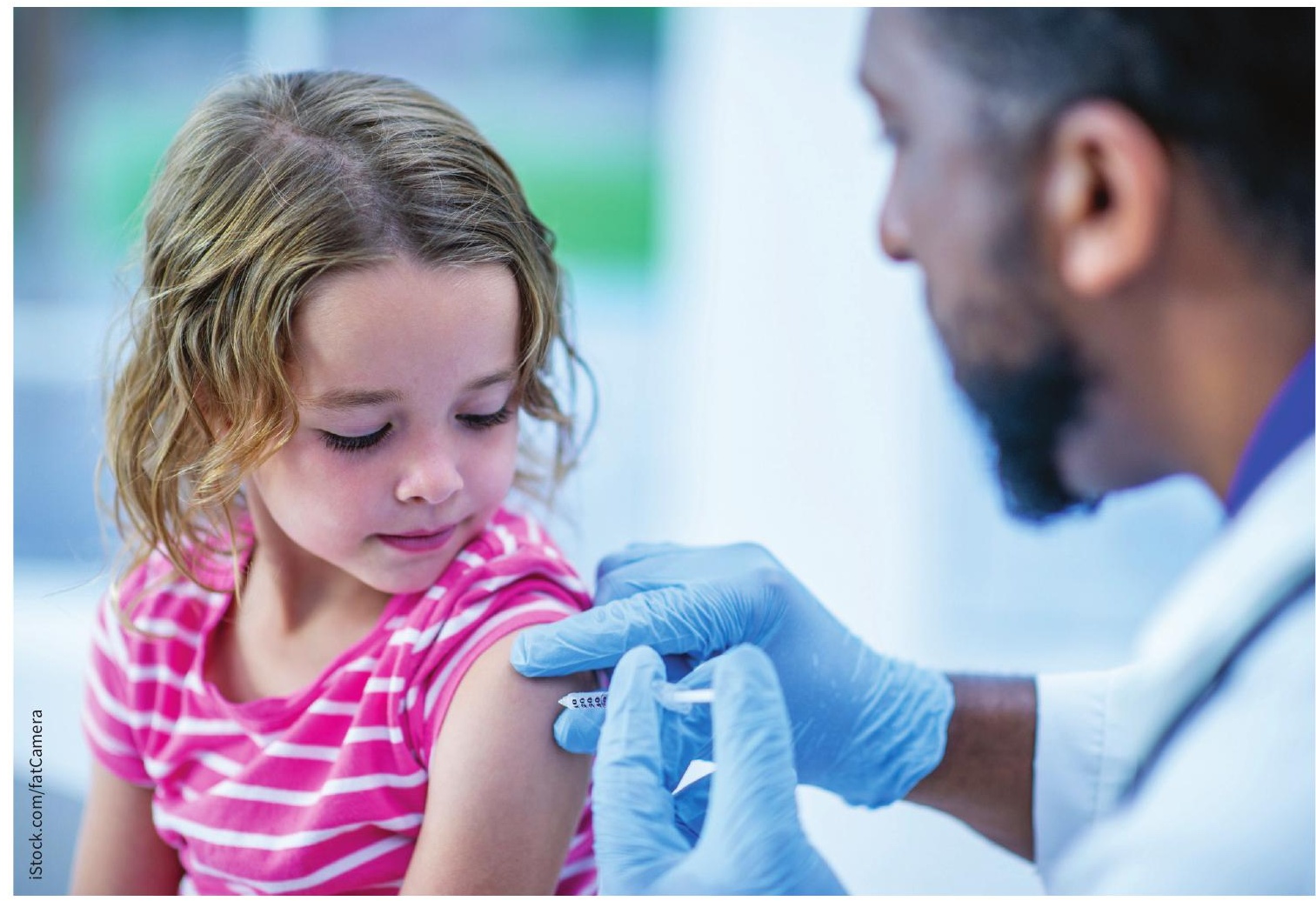

Mandatory vaccination in Mississippi led to $99.4 \%$ immunization coverage for children in kindergarten.

immunization coverage in kindergarten in 2017-2018, the highest in the United States. Canadian numbers compare poorly; the latest data, from 2015, show that at age seven, less than $75 \%$ of children have received all age-recommended vaccines.

There is, however, little outcome research data available on mandatory vaccination programs in other jurisdictions, which can sometimes spark increased avoidance and fuel the antivaccine movement.

"Some parents don't necessarily agree with getting their children vaccinated, and for that reason they chose to home school," said Levi. 
According to Ubaka Ogbogu, a University of Alberta law professor, "It might force parents to quit the medical system entirely." Of course many of these parents, he added, already avoid mainstream medicine so mandatory vaccination laws might have little effect on their decisions.

In a recent debate on the pros and cons of mandatory immunization with Ogbogu in AlbertaViews, Dr. Joan Robinson, a professor of pediatrics at the University of Alberta, said she fears that some parents would see legislated immunization as an infringement on their right to make health care decisions for their children, "leading to fury and increasing mistrust of the medical profession. As has happened in the US, it might be possible to find a physician in Alberta who would claim that a child has a contraindication to immunization even though this is not proven."

"I think this most likely won't happen," said Ogbogu, "I like to think that physicians are ethical professionals; they would not want to put their name on something that is not true. For that to happen, one would have to assume that physicians don't care about vaccinations and I don't think that that is the case."

In California, however, some physicians have even been caught turning medical exemptions into a lucrative business. The problem of parents shopping for exemptions in California prompted the creation of a bill that would give the State Department of Public Health the power to approve or reject medical exemptions submitted by physicians, creating a centralized system as in Mississippi and West Virginia. Cosponsors of the bill include the California Medical Association and the American Academy of Pediatrics, California.

The Canadian Paediatric Society said it does not have an official position on mandatory immunization. Vaccine Choice Canada, a group that opposes mandatory vaccination, said the decision to vaccinate a child should not be made by health authorities. "Parents ... should always maintain the right to make voluntary, informed decisions about all aspects of their child's health care, including vaccination," the group wrote in an email statement.

Marie-Claude Grégoire, Halifax, Nova Scotia 